\title{
Neurological involvement in legionellosis
}

\author{
AI WEIR, ${ }^{*}$ I BONE, ${ }^{*}$ DH KENNEDY $\dagger$ \\ From the University Department of Neurology, Institute of Neurological Sciences, Southern General \\ Hospital, ${ }^{*}$ and the Department of Infectious Diseases, Ruchill Hospital, $\dagger$ Glasgow, Scotland
}

SUMMARY A study of the clinical, electrophysiological and biochemical features of 16 patients with legionellosis has been performed. Evidence of central and peripheral nervous system involvement has been found in the majority of patients. This is characterised by confusion out of keeping with the degree of toxic or metabolic upset, signs of anterior midline cerebellar dysfunction, grossly elevated creatinine kinase of skeletal muscle origin, and a subclinical peripheral neuropathy.

Since the epidemic of severe pneumonia at an American Legion Convention in $1976^{1}$ the term legionnaires' disease has been associated with a serious respiratory system disorder. Infection with the causative pathogen, Legionella pneumophila is now more appropriately termed legionellosis to emphasise the multisystem features including pneumonia, abdominal distension and paralytic ileus, renal impairment, shock, icterus, coagulopathy and neurological upset..$^{1-3}$ In view of the difficulty of isolating the causative bacillus and the current dependence on serological testing for positive diagnosis the clinical features are crucial. This is important in view of the limited therapeutic options and high mortality in untreated cases. ${ }^{45}$

The neurological aspects have been described by several workers in case reports, ${ }^{25-15}$ but no comprehensive study has been made of these features. We report our findings of 16 cases of legionellosis which have been examined and investigated neurologically, out of a total of 28 which have passed through the infectious diseases and chest medicine units of Ruchill Hospital, Glasgow. We have briefly communicated our findings before ${ }^{1617}$ and two of the cases reported have also been described previously by Lees and Tyrrell. ${ }^{5}$ Our overall findings show features which appear distinctive and aid early diagnosis and appropriate management.

\footnotetext{
Address for reprint requests: Dr AI Weir, University Department of Neurology, Institute of Neurological Sciences, Southern General Hospital, Glasgow, G51 4TF, Scotland.
}

Received 28 January 1982

Accepted 7 March 1982

\section{Patients}

Of 16 cases (four fatal) known since 1973,11 were prospectively diagnosed by a significant antibody rise ( $\geqslant 4$ fold) and five were retrospectively diagnosed with a rising or late high titre (above 256). The diagnosis was confirmed by means of a polyvalent, indirect fluorescent antibody test already described..$^{18}$ In 14 cases, serology was positive against Legionella pneumophila type 1 antigen, whilst serological rises were obtained in single cases of type 2 and type 5 antigens respectively. Four case reports illustrate our findings.

Case 1 A 53-year-old woman was admitted to the chest medicine unit in August 1975. Towards the end of a holiday in Italy she had developed headache, productive cough and the rapid onset of confusion. On admission she was found to be pyrexial with signs of a right basal consolidation. There were no lateralising central or peripheral nervous system signs initially. Investigations revealed an ESR of $68 \mathrm{~mm}$ in one hour; blood cultures and virology to routine pathogens were negative. A chest radiograph showed a right basal consolidation. Treatment was instituted with intravenous ampicillin but she continued to deteriorate clinically. Over the next few days her confusional state worsened and she developed nuchal rigidity and a left extensor plantar response. Lumbar puncture revealed normal pressure, a normal protein and glucose, but 21 lymphocytes $/ \mathrm{mm}^{3}$. A CT scan was performed to exclude a cerebral abscess and was normal. Her blood urea became elevated to a maximum of $38 \mathrm{mmol} / \mathrm{l}$ and she was commenced first on peritoneal dialysis and then haemodialysis. Following this there was clinical improvement but it was noticed that her speech was slurred and, on mobilisation, she was clearly ataxic with poor tandem gait and lower limb heel-shin ataxia. She was discharged from hospital with the eventual diagnosis of an encephalitis of unknown aetiology producing toxaemia and acute renal failure. Two years later, stored serum was sent to the Centre for Disease Control at Atlanta, Georgia, USA and 
positive immunofluorescent antibody titres to Legionella pneumophila were demonstrated. She was reviewed neurologically 3 years after her illness and was found to have a severe scanning cerebellar dysarthria, a wide based gait with unsteadiness on turning, brisk limb reflexes, mild finger-nose ataxia and pronounced heel-shin ataxia. Visual evoked responses were performed which were normal and a repeat CT scan showed evidence of cerebellar atrophy.

Case 2 A 50-year-old man was admitted in September 1974 following a holiday in Benidorm. Six days prior to admission he had developed a progressive illness with diarrhoea, fever, headache and breathlessness associated with a cough and purulent sputum. On admission he was pyrexial $\left(39.3^{\circ} \mathrm{C}\right)$ and dyspnoeic. Auscultation revealed generalised rhonchi and coarse crepitations at the right lung base. He was also noted to be unsteady on his feet, confused and agitated and to have dysarthric speech. Investigations included a chest radiograph confirming a right middle and lower lobe consolidation and biochemical evidence of renal and hepatic impairment of function. Initial treatment with parenteral gentamycin and ampicillin had no clinical effect and the patient's confusion persisted. Without a change in treatment he made a gradual recovery but during convalescence he was noted to have an ataxic gait. He returned to work after one year as a security guard but eventually gave this up through instability of gait. Retrospective serological testing confirmed the diagnosis of legionellosis.

Case 3 A 55-year-old joiner was admitted in July 1979 with a 7 day history of cough, fever, myalgia and severe headache with diarrhoea. He had also developed unsteadiness of gait, dysarthria and become grossly hallucinated. On admission to hospital he was pyrexial $\left(38.8^{\circ} \mathrm{C}\right)$ and had a left lower lobe pneumonia. His investigations confirmed the pneumonia and also revealed extensive bilateral pulmonary oedema. Biochemistry revealed a degree of renal and hepatic impairment. During the acute phase of his illness an electroencephalogram showed diffuse slow wave activity felt to be in keeping with a toxic metabolic encephalopathy. Serum creatinine kinase was elevated at $958 \mathrm{IU} / \mathrm{l}$ (normal < 75 units) and isoenzymes studies showed this to be of skeletal muscle origin. Myoglobinurea was not detected. In this case legionellosis was suspected and the patient was treated with intravenous erythromycin and oral rifampicin producing a rapid recovery. The confusional state soon cleared and convalescent examination revealed no evidence of central or peripheral nervous system involvement.

Case 4 A 36-year-old man who because unwell during a holiday in Benidorm was admitted in September 1980 with a 7 day history or unproductive cough, nausea, diarrhoea, fever and dizziness. On the day prior to admission his relatives had noticed that his speech was becoming incomprehensible and that he was unsteady on his feet. On admission he was pyrexial $\left(40^{\circ} \mathrm{C}\right)$ and had a cough but was never dyspnoeic or cyanosed. Auscultation revealed coarse crepitations at the left base. Neurological examination revealed marked dysarthria, a wide based gait, mild heelshin ataxia but no finger-nose ataxia. His affect was felt to be facile but he was not confused on admission. Peripheral nervous system examination was normal. A presumptive diagnosis of legionellosis was made and he was commenced on $4 \mathrm{G}$ of erythromycin intravenously daily and on this treatment was afebrile within 12 hours. The next day however he became agitated and confused and had an exacerbation of his dysarthria. The restlessness resolved but speech disturbance persisted for 10 days. He also complained of difficulty with his balance during his convalescence. The creatinine kinase estimation on admission was $2,540 \mathrm{IU} / 1$ (normal < $75 \mathrm{IU}$ ) and this was of skeletal muscle origin. Urine testing for myoglobin was negative.

These four patients illustrate features that we have noticed with regularity in patients suffering from legionellosis. The findings are summarised in table 1 and are compared with their incidence in other pneumonias. Column A contains the legionellosis patients. Column B1 contains patients with non-legionnaires' pneumonia of known aetiology and column B2 contains patients with nonlegionnaires' pneumonia of undetermined aetiology. In 14 to 16 cases of legionellosis there was confusion out of keeping with the degree of metabolic upset. Frequently, this confusion was associated with hallucinations of both auditory and visual types. In eight of 16 patients there was disturbance of gait suggesting anterior and mid vermis cerebellar dsyfunction. There was also dysarthria suggesting an anterior cerebellar hemisphere lesion. ${ }^{19}$ Focal neurological signs were noted in three of the 16 patients but these could be explained on the basis of a concomitant vascular effect in patients suffering from an acute infection. In 10 patients who had serum creatinine kinase measured, $\underset{<}{\sigma}$ the level of the enzyme was grossly elevated with a mean for the whole group of 1,511 IU. The mean creatinine kinase level for pneumonias of known aetiology was 67 IU and pneumonias of unknown aetiology 133 IU.

In view of the myalgia, elevated creatinine kinase, and ? signs of a peripheral neuropathy in one of the 16 patients, nerve conduction studies and electromyography were performed on a sample group of six patients. All had no symptoms of involvement of the peripheral nervous system. The study was repeated in two of these patients after approximately 4 months. The first investigation was performed 8 to 34 days after admission (mean 19 days) and 21 to 39 days (mean 29 days) after the onset of symptoms. Standard techniques were used for measurement from surface electrodes of the shortest distal motor latency and

Table 1

\begin{tabular}{lrll}
\hline & $A$ & $B_{1}$ & $B_{2}$ \\
\hline Confusion & $14 / 16$ & $2 / 6 \dagger$ & $3 / 14^{*}$ \\
Hallucination & $8 / 16$ & $1 / 6 \dagger$ & - \\
Ataxia & $8 / 16$ & $1 / 6$ & - \\
Dysarthria & $8 / 16$ & $1 / 6$ & - \\
Focal signs & $3 / 16$ & - & $4 / 14$ \\
Creatinine kinase elevated & $10 / 10$ & - & \\
$\quad<300$ iu & $1 / 10$ & & \\
$300-700$ iu & $7 / 10$ & & \\
$\quad>700$ iu & $6 / 16$ & & \\
ND & 1511 iu & 67 iu & 133 iu \\
Mean CK & & & \\
\hline
\end{tabular}

*All $>70$ yrs.

† History of alcohol excess.

$A=$ Legionnaires' disease, $B_{1}=$ Non legionnaires' pneumoniaaetiology known, $B_{2}=$ Non legionnnaires' pneumonia-aetiology unknown, ND $=$ Not determined. 
fastest motor conduction velocity of the right common peroneal nerve in each case. ${ }^{20}$ Skin temperature was maintained at $33^{\circ} \mathrm{C}$ in a thermostatically controlled room in all cases. The sural sensory potential was recorded orthodromically with surface electrodes in four of the six patients. Results were compared with an age matched control group and are shown in table 2 .

The mean fastest motor nerve conduction velocity in the common peroneal nerve on the first examination was not different from that in the control group. The mean shortest distal motor latency was prolonged compared with the control group ( $t$ test $\mathrm{p}=<0.007$ ). The amplitude of the evoked muscle action potential was normal in five patients but was reduced in one other patient some 39 days after onset of symptoms. The sural sensory potential was within normal limits whilst the sensory potential amplitude small in one of the four tested.

Table 3 summarises the results of needle electromyography. Three to six muscles were sampled in the upper and lower limbs proximally and distally. At the first examina- tion four patients showed fibrillation in one or more distal muscles. One patient had normal amplitude voluntary motor unit potentials, but another had a reduced mean amplitude, and four others had an increased mean motor unit potential amplitude. The patient with the small amplitude polyphasic units (No 6) was seen some 39 days from onset of symptoms. Five patients had excessive numbers of polyphasic units and these were increased in duration in four of the five. In all six patients there was a reduction in the interference pattern. These results were interpreted to indicate the presence of a subclinical distal axonal neuropathy, predominantly affecting motor axons, with active reinnervation. In view of this conclusion it was important to exclude the patient's drug therapy as a possible cause of such a neuropathy. All six patients were on some form of medication either before or at the time of neurophysiological examination. The drugs were erythromycin, dexamethasone, penicillin, rifampicin, talampicillin, vibramycin and solbutamol. Only dexamethasone has a documented effect on the peripheral nervous system. ${ }^{21}$ None of the

Table 2 Motor and sensory nerve conduction studies

\begin{tabular}{|c|c|c|c|c|c|c|c|}
\hline \multirow[t]{2}{*}{ Patient } & \multirow{2}{*}{$\begin{array}{l}\text { Age } \\
y r\end{array}$} & \multirow{2}{*}{$\begin{array}{l}\text { Days after } \\
\text { onset }\end{array}$} & \multicolumn{3}{|c|}{ Common peroneal nerve* } & \multicolumn{2}{|l|}{ Sural nerve $\dagger$} \\
\hline & & & $S D M L m s$ & Amplitude $\mathrm{mV}$ & $F M N C V \mathrm{~m} / \mathrm{s}$ & Distal latency $\mathrm{ms}$ & Amplitude mV \\
\hline $\begin{array}{l}1 \\
2 \\
3 \\
4 \\
5 \mathrm{i} \\
\quad \mathrm{ii} \\
6 \mathrm{i} \\
\mathrm{ii}\end{array}$ & $\begin{array}{l}40 \\
36 \\
57 \\
52 \\
53 \\
\\
51\end{array}$ & $\begin{array}{c}34 \\
21 \\
>24 \\
24 \\
8 \\
4 \text { months } \\
39 \\
51 / 2 \text { months }\end{array}$ & $\begin{array}{l}4 \cdot 3 \\
4 \cdot 9 \\
4 \cdot 55 \\
3 \cdot 4 \\
4 \cdot 6 \\
(3 \cdot 6) \\
5 \cdot 0 \\
(4 \cdot 6)\end{array}$ & $\begin{array}{c}7 \cdot 0 \\
14 \cdot 0 \\
9 \cdot 0 \\
\text { NR } \\
6 \cdot 4 \\
\text { NR } \\
0 \cdot 6 \\
5\end{array}$ & $\begin{array}{l}46 \cdot 1 \\
45 \cdot 7 \\
46 \cdot 0 \\
44 \cdot 5 \\
50 \\
45 \cdot 5 \\
50 \\
47\end{array}$ & $\begin{array}{l}4 \cdot 4 \\
4 \cdot 2 \\
4 \cdot 6 \\
\text { NR } \\
\text { NR } \\
\text { NR } \\
\text { Absent } \\
2 \cdot 8\end{array}$ & $\begin{array}{l}8 \\
2 \cdot 5 \\
4 \\
\text { NR } \\
\text { NR } \\
\text { NR } \\
\\
12\end{array}$ \\
\hline $\begin{array}{l}\text { Mean } \\
\text { SD }\end{array}$ & $\begin{array}{l}48.1 \\
\pm 7.5\end{array}$ & & $\begin{array}{r}4.46 \\
\pm 0.58\end{array}$ & $\begin{array}{r}7 \cdot 4 \\
+4 \cdot 8\end{array}$ & $\begin{array}{r}47.05 \\
\pm 2.35\end{array}$ & & \\
\hline $\begin{array}{l}\text { Control mean } \\
S D \\
(N=29)\end{array}$ & $\begin{array}{r}51.4 \\
\pm 13.3\end{array}$ & & $\begin{array}{r}3.71 \\
\pm 0.51\end{array}$ & $\begin{array}{r}7.15 \\
\pm 3.36\end{array}$ & $\begin{array}{l}49.0 \\
\pm 5.17\end{array}$ & $<5$ & $\begin{array}{l}10 \ddagger \\
4-27 \\
(95 \% \mathrm{CL})\end{array}$ \\
\hline$t$ test & & & 0.007 & NS & NS & & \\
\hline
\end{tabular}

*SDML $=$ shortest distal motor latency.

Amplitude = supramaximal evoked muscle action potential in extensor digitorum brevis.

FMNCV = fastest motor nerve conduction velocity.

tOrthodromic recording of sural sensory potential.

Distal latency stimulating all lateral malleolus and recording between heads of gastrocnemius.

$\ddagger$ Control values for sensory potential from Rosenfalck P. Electromyography: sensory and motor conduction. Copenhagen: Rigshospitalet 20.

NR $=$ Not recorded.

Table 3 Electromyography

\begin{tabular}{|c|c|c|c|c|c|}
\hline Patient & Fibrillation & $\begin{array}{l}\text { Motor unit potential* } \\
\text { amplitude }\end{array}$ & $\begin{array}{l}\text { Polyphasic* } \\
\text { units }\end{array}$ & $\begin{array}{l}\text { Motor unit potential } \\
\text { duration }\end{array}$ & $\begin{array}{l}\text { Interference } \\
\text { patterns }\end{array}$ \\
\hline $\begin{array}{l}1 \\
2 \\
3 \\
4 \\
5 \mathrm{i} \\
\mathrm{ii} \\
6 \mathrm{i} \\
\mathrm{ii}\end{array}$ & $\begin{array}{l}0 \\
+ \\
+ \\
+ \\
+ \\
\text { NR } \\
0 \\
+\end{array}$ & $\begin{array}{l}>\mathbf{N} \\
>\mathbf{N} \\
>\mathbf{N} \\
\mathbf{N} \\
>\mathbf{N} \\
<\mathbf{N} \\
\mathbf{N}\end{array}$ & $\begin{array}{l}0 \\
++ \\
+++ \\
++ \\
++ \\
++ \\
+++\end{array}$ & $\begin{array}{l}\mathbf{N} \\
>\mathbf{N} \\
>\mathbf{N} \\
>\mathbf{N} \\
\mathbf{N} \\
>\mathbf{N} \\
>\mathbf{N}\end{array}$ & $\begin{array}{l}\mathbf{R} \\
\mathbf{R} \\
\mathbf{R} \\
\text { SR } \\
\text { SR } \\
\mathbf{R} \\
\text { SR }\end{array}$ \\
\hline
\end{tabular}

*Absolute values depend on muscle, age, electrode placement.

$0=$ None, $+=$ Occasional, $++=$ Frequent, $+++=$ Majority, $\mathbf{N}=$ Normal for muscle tested, $>\mathbf{N}=\mathrm{Greater}$ than normal, $<\mathrm{N}=$ Less than normal, $\mathrm{SR}=$ Slightly reduced, $\mathrm{R}=$ Significantly reduced, $\mathbf{N R}=$ Not recorded. 
drugs quoted cause a peripheral neuropathy of the type described here.

Electroencephalographic studies carried out in five patients during the acute phase of the illness showed diffuse delta activity in four with frequencies as low as $1.5 \mathrm{~Hz}$. All records examined acutely were compatible with an acute toxic or metabolic dysfunction and could not be explained on the basis of the blood gas or electrolyte upset. ${ }^{22}$ The cerebrospinal fluid was examined only on one occasion, revealing a lymphocytosis. In the four patients with elevated creatinine kinase the urine was examined for myoglobinurea but this was not detected.

\section{Discussion}

There have been many reports in the literature of this new disease which emphasise neurological involvement, but there has been no large prospective study of patients. A depression of conscious level and personality changes at the onset of the disease have been described. ${ }^{11}$ Confusion, delirium and hallucinations disproportionate to metabolic upset in terms of fever, hypoxaemia and hypernatraemia have also been described. ${ }^{21314}$ In one study of 24 patients with legionellosis, 11 had such mental abnormalities, although they were only seen in one of 10 patients with pneumonias of different aetiologies. ${ }^{15}$ Accompanying features of meningism have been described as well as papilloedema ${ }^{19}$ and a 6th nerve palsy. ${ }^{10}$ CSF examinations have failed to add support to the diagnosis of meningoencephalitis; in only one reported case has it been abnormal with 10 mononuclear cells per cubic millimetre. ${ }^{13}$ Focal neurological dysfunction has been described in legionellosis previously. ${ }^{5}$ Terranova et al first described the persisting ataxia in legionellosis $^{9}$ and this has been supported by further cases. $^{612}$ A case report describing cerebellar and brain stem dysfunction has been rather complicated by the possible effects of the patients known psychotrophic drug therapy. ${ }^{8}$ Landry-Guillain-Barre neuropathy had been described in two patients with legionellosis. ${ }^{7}$ All these case reports and our own comprehensive study raise questions as to the aetiology of the abnormalities described.

Cerebellar ataxia is well recognised in infections with Echo, Coxsackie, polio and herpes virus infections. ${ }^{23}$ It is also seen in infectious mononucleosis and epidemic encephalitis. ${ }^{23}$ In all these cases the abnormality is probably due to direct nervous system involvement with the organism. Ataxia can also occur as part of an acute disseminated encephalomyelitis ${ }^{24}$ following exanthemata (particularly chicken-pox), and non-viral infection may give rise to an acute ataxia for example during a $M y c o-$ plasma pneumoniae infection..$^{25} 26$ This latter organism is of particular interest as there is a reported $2 \%$ incidence of neurological involvement. ${ }^{27}$ The pathogenesis is thought to be an unknown toxin or a cross reactivity of brain and mycoplasma antigens, ${ }^{28}$ an immune complex disease, ${ }^{26}$ or a generalised vasculopathy. ${ }^{29}$

A further striking feature requiring explanation is the high serum creatinine kinase enzyme of skeletal muscle origin. A high creatinine kinase level has been reported before, ${ }^{11}$ but no study has been made simultaneously in other pneumonias. A single case of legionellosis has been reported with a creatinine kinase level of 10,700 IU/l (normal $75 \mathrm{IU}$ ) and myoglobinuria was detected. ${ }^{30}$ Muscle biopsy features showed rhabdomyolysis. In our cases there was consistent elevation of creatinine kinase but a single muscle biopsy was reported to be normal. The severity of the illness in the acute stage precluded biopsy in all but this one convalescent patient. The elevation of the enzyme is evidence of direct muscle damage; it was much greater than that likely to occur with the subclinical neuropathy detected electrophysiologically. Posner reported immunofluorescent antibody studies in skeletal muscle and, because of the negative conclusion, felt there was no direct bacterial invasion. The presence of a bacterial product such as an endotoxin-like agent has been postulated $^{3132}$ and this might reasonably be the origin of acute damage to both muscle and axonal membranes due to complement activation.

Polyneuropathy and radiculopathy have beenco described as complications of viral and bacterial infections. The organism may directly damage the nerve as in the distal sensory polyneuritis or mononeuritis multiplex of leprosy. ${ }^{33} \mathrm{~A}$ toxic polyneuropathy may be produced as a result of infection with Corynebacteriam diphtheriae and the pathological lesion attributed to the toxin is characterised by destruction of myelin sheaths with preservation of the axon in continuity. ${ }^{34}$ The resulting electrophysiology is of gross slowing of conduction without muscle fibre denervation. ${ }^{35}$ An allergic polyneuritis (Landry-Guillain-Barré syndrome) is a recognised complication of viral, mycoplasma and bacterial infection. Electrophysiology in this condition produces both demyelinating and axonal features. ${ }^{36}$ Finally secondary ischaemia may play a role in the neuropathy of infective illnesses if there is obstruction to the vasa nervorum such as in the disseminated intravascular coagulation associated with a Mycoplasma pneumoniae infection; electrophysiologically this can produce both demyelinating and axonal changes. ${ }^{37}$

The electrophysiological features in the patients with legionellosis cannot be fitted clearly into any of the above categories. The neuropathy seems characterised by a rapid loss of some motor axons causing a 
mild drop in conduction velocity, particularly distally, with some denervation and rapid reinnervation. The recovery is underlined by the improvement of the shortest distal motor latencies in both patients that were seen after four months, and the re-appearance of the sural sensory potential in one. The pathophysiological process is far more like the neuropathy due to a toxic insult often described as a "dying back" neuropathy. ${ }^{38}$

We have shown evidence of involvement of both central and peripheral nervous systems in legionellosis. We have already stated Posner's evidence for the absence of direct invasion by the organism and the multiple system involvement would make crossed reactivity of an organ such as brain with Legionella pneumophila antigens improbable. The most attractive mechanism would seem to be the production of an endotoxin-like agent which produces multi-organ damage.

We are grateful for the co-operation of $\mathrm{Dr} W C$ Love, Dr IW Pinkerton, Dr AW Lees and Dr W Tyrrell for graciously allowing us to include their cases in this report. We are also grateful to $\mathrm{Mr} \mathrm{W}$ Borland and Dr BF Allam for the biochemical studies, and Dr RG Fallon, Dr WH Abraham for the serology. Dr Weir acknowledges the support of the Wellcome Trust.

\section{References}

' Fraser DW, Tsai TR, Orenstein W, et al. Legionnaires' disease. Description of an epidemic of pneumonia. $N$ Engl J Med 1977;297:1189-97.

${ }^{2}$ Gregory DW, Schaffner W, Alford RH, et al. Sporadic cases of Legionnaires' disease: The expanding clinical spectrum. Ann Int Med 1979;90:518-21.

${ }^{3}$ Gasper TM, Farndon PA, Davies R. Thrombocytopenia associated with Legionnaires' disease. $\mathrm{Br} \mathrm{Med} J$ 1978;1611-12.

4 Sanford JP. Legionnaires' Disease: One person's perspective. Ann Int Med 1979;90:699-703.

${ }^{5}$ Lees AW, Tyrrell WF. Severe Cerebral disturbance in legionnaires' disease. Lancet 1978;ii:1336-7.

${ }^{6}$ Maskill MR, Jordan EC. Pronounced cerebellar features in Legionnaires' disease. $\mathrm{Br} \mathrm{Med} J$ 1981;283:276.

${ }^{7}$ Morgan DJR, Gawlor J. Severe peripheral neuropathy complicating legionnaires' disease. $\mathrm{Br} M e d \mathrm{~J}$ 1981;283:1577-8.

${ }^{8}$ Baker PCH, Price TRP, Allen CD. Brainstem and cerebellar dysfunction with legionnaires' disease. $J$ Neurol Neurosurg Psychiatry 1981;44:1054-6.

9 Terranova W, Cohen ML, Fraser DW. 1974 Outbreak of Legionnaires' disease diagnosed in 1977-clinical and epidemiological features. Lancet 1978;ii:122-4.

${ }^{10}$ Lattimer GL, Rhodes LV III. Legionnaires' disease.
Clinical findings and one year follow up. J Am Med Assoc 1978;240:1169-71.

"Freidman MH. Legionnaires' disease in nonlegionnaires; A report of five cases. Ann Int Med 1977;88:294-302.

${ }^{12}$ Shetty KR, Cilyo CL, Starr BD, Haster DH. Legionnaires' disease with profound cerebellar involvement. Arch Neurol 1980;39:379-80.

${ }^{13}$ Tsai TF, Finn DR, Plikaytis BD, et al. Legionnaires' disease: Clinical features of the epidemic in Philadelphia. Ann Int Med 1979;90:509-17.

${ }^{14}$ Meenhorst PL, van der Meer JWM, Borst J. Sporadic cases of legionnaires' disease in the Netherlands. Ann Int Med 1979;90:529-32.

${ }^{15}$ Sharrar RG, Friedman HM, Miller WT, et al. Summertime pneumonias in Philadelphia 1976. Ann Int Med 1979;90:577-80.

${ }^{16}$ Kennedy DH, Bone I, Weir AI. Early diagnosis of legionnaires' disease: distinctive neurological findings. Lancet 1981;: :940-1.

${ }^{17}$ Bone I, Weir AI, Kennedy DH. Pronounced cerebellar features in legionnaires' disease. $\mathrm{Br}$ Med $J$ 1981;283:730.

${ }^{18}$ Fallon RJ, Abraham WH. Detecting legionnaires' disease. Lancet 1978;ii:1318.

${ }^{19}$ Brown JR, Darley FL, Aronson AE. Ataxic dysarthria. Int J Neurol 1970;7:302.

${ }^{20}$ Lenman JAR, Ritchie AE. Clinical Electromyography, 2nd ed. Bath: Pitman, 1977:60-2.

${ }^{21}$ Leeuwin RS, Wolters EchMJ. Effect of corticosteroids on sciatic nerve-tibialis anterior muscle of rats treated with hemicholinium-3. Neurology (Minneap) 1977;27:171-7.

${ }^{22}$ Kiloh LG, McComas AJ, Osselton JW, Upton ARM. Clinical Electroencephalography. London: Butterworths 1981: 168-70.

${ }^{23}$ Weiss S, Guberman A. Acute cerebellar ataxia in infectious disease. In: Vinkem PJ, Bruyn GW, eds. Handbook of Clinical Neurology 34 ii. Amsterdam: North Holland Publishing Company, 619-39.

${ }^{24}$ Griffith G. Neurological complications of some infectious diseases. Edinburgh Medical J 1952;59:492503.

${ }^{25}$ Sangster G. Neurological complications of primary atypical pneumonia. Br J Clin Pract 1966;20:89-92.

${ }^{26}$ Behan PO, Feldman RG. Neurological disease and mycoplasma infections. Arch Neurol 1982; in press.

${ }^{27}$ Noah ND. Mycoplasma pneumoniae infection in the United Kingdom. Br Med J 1974;ii:544-6.

${ }^{28}$ Biberfield G. Antibodies to brain and other tissues in cases of Mycoplasma pneumoniae infection. Clin Exp Immunol 1971;8:319-33.

${ }^{29}$ Manuelidis EE, Thomas L. Occlusion of brain capillaries by endothelial swelling in mycoplasma infection. Proc Natl Acad Sci (USA) 1973;70:706-9.

${ }^{30}$ Posner MR, Caudill MA, Brass R, Ellis E. Legionnaires' disease associated with rhabdomyolysis and myoglobinuria. Arch Int Med 1980;140:848-50.

${ }^{31}$ Wong $\mathrm{KH}$, Moss CW, Hochstein DH, et al. 'Endotoxicity' of the Legionnaires' disease bacterium. Ann Int Med 1979;90:624-7.

${ }^{32}$ Highsmith AIC, Mackel DC, Baine WB, et al. Observa- 
tions of endotoxin like activity associated with the Legionnaires' disease bacterium. Current Microbiol 1978;1:315-7.

${ }^{33}$ Rosenberg RN, Lovelace RE. Mononeuritis multiplex in lepromatous leprosy. Arch Neurol 1968;19:310.

${ }^{34}$ McDonald WI. The effects of experimental demyelination in conduction in peripheral nerve: a histological and electrophysiological study 1 . Clinical and histological observations. Brain 1963;86:481-500.
${ }^{35}$ McDonald WL. Ibid ii. Electrophysiological observations. Brain 1963;86:501-24.

${ }^{36}$ Lambert EH, Mulder DW. Nerve conduction in the Guillain-Barre syndrome (abstr.). Int EMG Conf 1962; Copenhagen 16-17.

${ }^{37}$ Pallis CA, Scott JT. Peripheral neuropathy in rheumatoid arthritis. $\mathrm{Br}$ Med J 1965;i:1141-7.

${ }^{38}$ Fullerton PM, Barnes JM. Peripheral neuropathy in rats produced by acrylamide. $\mathrm{Br} J$ Indust Med 1966;23:210. 